\title{
Sensitive electrochemical determination of Cefpirome in human urine using differential pulse voltammetry
}

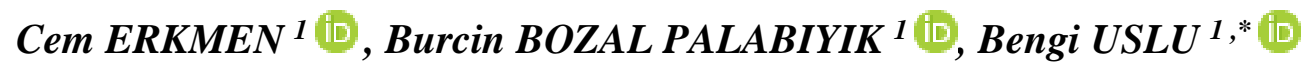 \\ ${ }^{I}$ Ankara University, Faculty of Pharmacy, Department of Analytical Chemistry, 06560, Ankara / TURKEY
}

\begin{abstract}
Cefpirome, which is a fourth-generation cephalosporin, was analyzed for the first time at a glassy carbon electrode using differential pulse voltammetry in this novel method. Different experimental conditions were optimized, such as $\mathrm{pH}$ and electrolyte type, to achieve a high peak current. Under the optimum conditions, the oxidation of cefpirome exhibited diffusioncontrolled process depending on $\mathrm{pH}$. Cefpirome was electrochemically determined at the linear range between $2-200 \mu \mathrm{M}$, and the detection limit was found as $0.167 \mu \mathrm{M}$ in $\mathrm{pH} 4.7$ acetate buffer solution. Analysis results showed that the proposed electrochemical method could be used for the determination of cefpirome in human urine samples. A linear relationship has been obtained in the concentration range of $2-10 \mu \mathrm{M}$. At the same time, the detection limit was found as $0.101 \mu \mathrm{M}$ for cefpirome in human urine. Moreover, to check the selectivity of the proposed method, the effect of some interference species, including ascorbic acid, uric acid, dopamine, glucose, $\mathrm{Na}^{+}, \mathrm{K}^{+}, \mathrm{Ca}^{+2}, \mathrm{NO}_{3}^{-}$, have also been investigated. As a result, a simple, sensitive, reproducible, no time-consuming, and more environmentally friendly method was developed when compared to the literature studies.
\end{abstract}

\section{Article info}

History:

Received: 21.03.2021

Accepted: 04.07.2021

Keywords:

Cefpirome,

Differential pulse

Voltammetry,

Electrochemistry,

Human urine,

Validation.

\section{Introduction}

Since the discovery of penicillin in 1928 , numerous antibiotics have been investigated and introduced for the treatment of various bacterial and fungal infections in humans or livestock. Cephalosporins are classified as one of the semisynthetic antibiotics. They are produced from the side-chain of cephalosporin $\mathrm{C}$, and cephalosporin $\mathrm{C}$ exhibits resistance to degradation caused by $\beta$-lactamases [1,2]. Cefpirome (Figure 1) is a fourth-generation cephalosporin, and it is generally used parenterally. In the chemical structure of cefpirome, there is a 2-amino-thiazolylmethoxyimino group in the side chain at position 7 and a cyclopentapyridine group at position 3, which are responsible for the side effect of antibacterial activity of cefpirome [3,4]. Moreover, the high level of resistance to $\beta$-lactamases stems from these elements present in the structure of cefpirome. Cefpirome is highly active against Gram-negative bacteria, including Pseudomonas aeruginosa, and Grampositive bacteria such as Staphylococcus aureus. Furthermore, cefpirome can effectively treat infections of skin and soft tissue, lower respiratory tract, and upper or lower urinary tract [4].

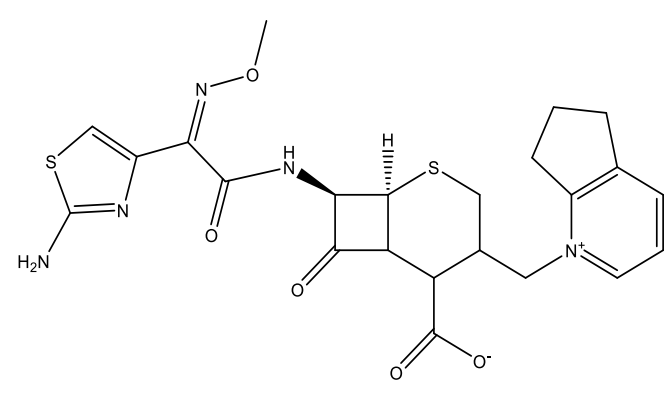

Figure 1. Chemical structure of cefpirome.

Previous studies demonstrate different analytical methods for the detection and determination of cefpirome in bulk form and from biological fluids such as serum, urine, milk, and muscle. These methods include liquid chromatography-tandem mass spectrometry (LC-MS/MS) [5,6], high-performance liquid chromatography (HPLC) [7-10] and reversed phase thin-layer chromatography [10], and electrochemical methods including differential pulse voltammetry (DPV) and square wave voltammetry (SWV) [4]. In their study, Jain and Vikas used multiwalled carbon nanotube modified glassy carbon electrode (GCE) for the determination of cefpirome in bulk form and pharmaceutical formulation. The linear range of $200-600 \mu \mathrm{g} \mathrm{mL}^{-1}$ was obtained by using both SWV and DPV. They found the detection limit as 
$0.647 \mu \mathrm{g} \mathrm{mL}^{-1}$ via SWV method and $5.540 \mu \mathrm{g} \mathrm{mL}$ via DPV method [4]. Although chromatographic methods are widely used for the determination of several compounds, these methods can be costly due to the necessity of sample separation and pretreatment steps. Also, chromatographic methods require a large amount of organic solvents and generate considerable amount of waste, leading to environmental degradation. Moreover, the major drawback of chromatographic methods is inability to achieve sensitive results [11-13]. Electrochemical methods are the most popular methods due to their advantages such as simplicity, rapidity, high sensitivity, low cost, and easy integration. These methods are more eco-friendly than other methods since they require low amounts of analytes and solvents. Moreover, lower detection limits, good repeatability, and reproducibility resulted in a growing interest in electrochemical methods [1417].

A GCE is an excellent electrode for different applications as a conventional electrode material. It has excellent mechanical and electrical properties. Also, it provides the opportunity to work at a wide operating potential range. GCE is also significant for its low reactivity (high corrosion resistance) compared to the other electrodes. Its most important properties are high temperature resistance, extreme resistance to chemical attack, and impermeability to gases and liquids $[18,19]$.

In this study, a DPV method was developed and validated according to ICH guidelines [20] at GCE for the sensitive detection and determination of cefpirome from bulk form. Since $80 \%$ of cefpirome is excreted unchanged from urine [21], its determination from human urine samples was also applied. Furthermore, to check the selectivity of the proposed method, the influence of potential foreign compounds on the determination of cefpirome in the optimum conditions was investigated. The developed method exhibited high sensitive results and good reproducibility for cefpirome detection in bulk form and human urine samples. Moreover, the advantages of the proposed method were compared to previously published studies.

\section{Materials and Methods}

\subsection{Apparatus and reagents}

In this study, an AUTOLAB-PGSTAT204 electrochemical and electroanalytical device was used to obtain cyclic and differential pulse voltammograms (Eco Chemie, Utrecht, The Netherlands). NOVA 2.1 software was used for data processing. GCE was used as a working electrode (BASi; ø: $3 \mathrm{~mm}$, diameter).
$\mathrm{Ag} / \mathrm{AgCl}(\mathrm{BASi} ; 3 \mathrm{M} \mathrm{KCl})$ and a platinum wire (BASi) were used as a reference electrode and an auxiliary electrode, respectively. A Mettler Toledo MA $235 \mathrm{pH}$ meter that includes a glass electrode-reference electrode was used for all $\mathrm{pH}$ measurements (Mettler Toledo TR Olcum Aletleri Tic. Satıs ve Servis Hizm. A.S. Istanbul, Turkey).

Cefpirome was purchased from CHEMOS GmbH (Regenstauf, Germany). A stock solution of cefpirome $\left(1 \times 10^{-3} \mathrm{M}\right)$ was prepared in bi-distilled water and kept in a refrigerator. Working solutions of cefpirome were prepared by diluting the stock solution with desired buffer solutions for voltammetric measurements. In this study, $0.1 \mathrm{M} \mathrm{H}_{2} \mathrm{SO}_{4}$ solution, $0.5 \mathrm{M} \mathrm{H}_{2} \mathrm{SO}_{4}$ solution, phosphate buffer solution (PBS) for $\mathrm{pH} 2.0$, 3.0 and 6.0-8.0, acetate buffer solution (ABS) for $\mathrm{pH}$ 3.7-5.7, Britton-Robinson buffer solution (BRB) for $\mathrm{pH}$ 2.0-12.0 were used as supporting electrolytes. To prepare supporting electrolytes, $\mathrm{CH}_{3} \mathrm{COOH}$ and $\mathrm{H}_{2} \mathrm{SO}_{4}$ were purchased from Merck. $\mathrm{H}_{3} \mathrm{PO}_{4}$ and analytical grade of $\mathrm{NaH}_{2} \mathrm{PO}_{4} \cdot 2 \mathrm{H}_{2} \mathrm{O}, \mathrm{Na}_{2} \mathrm{HPO}_{4}, \mathrm{NaOH}$, and $\mathrm{H}_{3} \mathrm{BO}_{3}$ were purchased from Riedel-de Haen.

\subsection{Assay procedure for cefpirome}

An adequate amount of cefpirome powder was carefully weighed, dissolved in bi-distilled water, and sonicated to prepare the stock solution $\left(1.0 \times 10^{-3} \mathrm{M}\right)$. Working solutions were prepared by diluting with $\mathrm{pH}$ 4.7 ABS. Before each measurement, the GCE surface cleaning process was carried out mechanically on a polishing pad using alumina slurry. Then, it was rinsed with bi-distilled water and allowed to dry in the air. DPV conditions were as follows; $0.005 \mathrm{~V}$ as a step potential; $0.025 \mathrm{~V}$ as a modulation amplitude; $0.05 \mathrm{~s}$ as a modulation time; $0.40 \mathrm{~s}$ as an interval time, and DP voltammograms were recorded using GCE to prepare the calibration graph. Furthermore, he proposed DPV method for the determination of cefpirome was validated through assessment of linearity, precision, the limit of detection (LOD), and the limit of quantification (LOQ).

\subsection{Determination of cefpirome in human urine sample}

Drug-free human urine samples were supplied from healthy volunteers. To prepare cefpirome stock solution in urine samples, $3.6 \mathrm{~mL}$ urine sample and 5.4 $\mathrm{mL}$ acetonitrile for protein precipitation were added into a $10.0 \mathrm{~mL}$ centrifuge tube. Then $1.0 \mathrm{~mL} 1.0 \times 10^{-3}$ $M$ stock cefpirome solution was added into this tube to obtain a final concentration of $1.0 \times 10^{-4} \mathrm{M}$ cefpirome. The same procedure was used for drug-free urine as a blank solution. Firstly, the prepared solution was sonicated for $15 \mathrm{~min}$ in the ultrasonic bath. Then, this 
sample was centrifuged for $15 \mathrm{~min}$ at $5000 \mathrm{rpm}$ to obtain the supernatant. Required volumes of clear supernatant were diluted up with $\mathrm{pH} 4.7 \mathrm{ABS}$. The working concentrations of cefpirome were prepared in the range of $2-10 \mu \mathrm{M}$ in human urine samples. The calibration graph was obtained using peak currents corresponding to cefpirome concentrations. Moreover, the recovery results were investigated using a calibration graph in urine samples.

\section{Results and Discussion}

\subsection{Influence of the $\mathrm{pH}$ on the peak currents}

The electrooxidation behavior of cefpirome was investigated over a $\mathrm{pH}$ range of $0.3-12.0$ various
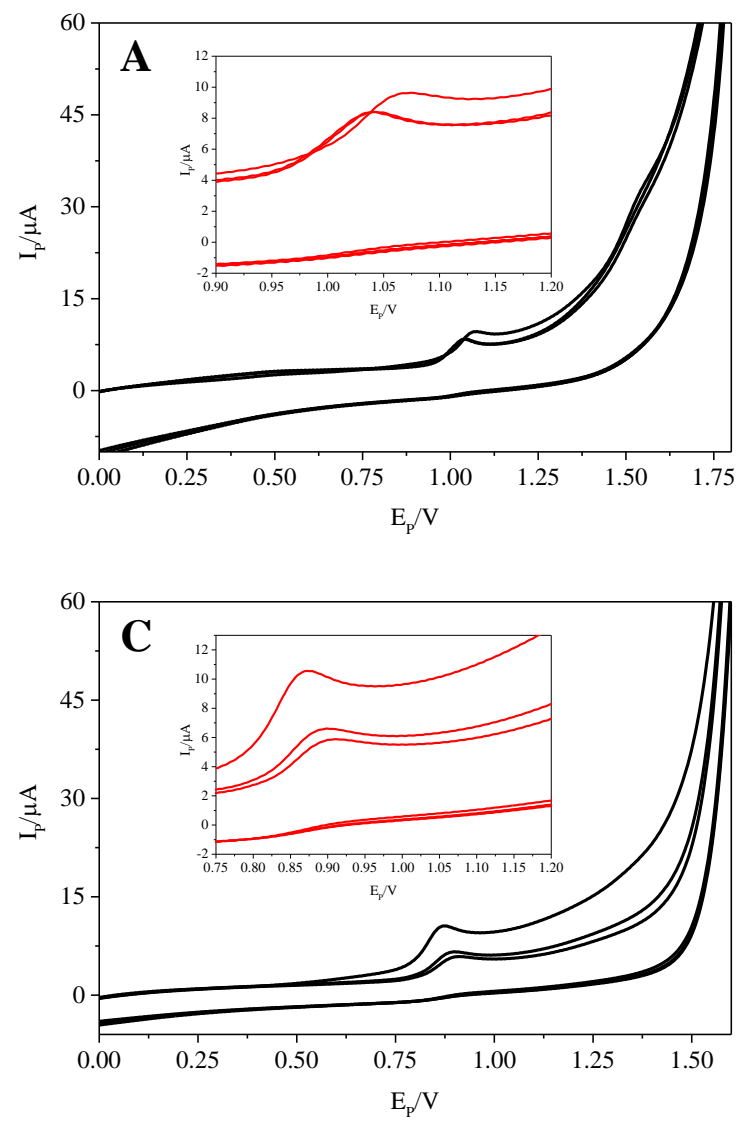

supporting electrolytes such as $0.1 \mathrm{M}$ and $0.5 \mathrm{M} \mathrm{H}_{2} \mathrm{SO}_{4}$ solutions and buffer solutions, including ABS, PBS, and BRB. The cyclic voltammograms of cefpirome at GCE in $0.1 \mathrm{M} \mathrm{H}_{2} \mathrm{SO}_{4}$, pH 2.0 BRB, pH 4.7 ABS and $\mathrm{pH}$ 7.0 PBS were shown in Figure 2A, B, C and D, respectively. As can be seen, no peak was observed in the reverse scan suggesting that the oxidation of cefpirome at GCE is irreversible. Cefpirome peak currents decreased by the second and consecutive cycles as a result of the consumption of adsorbed cefpirome on the electrode surface.
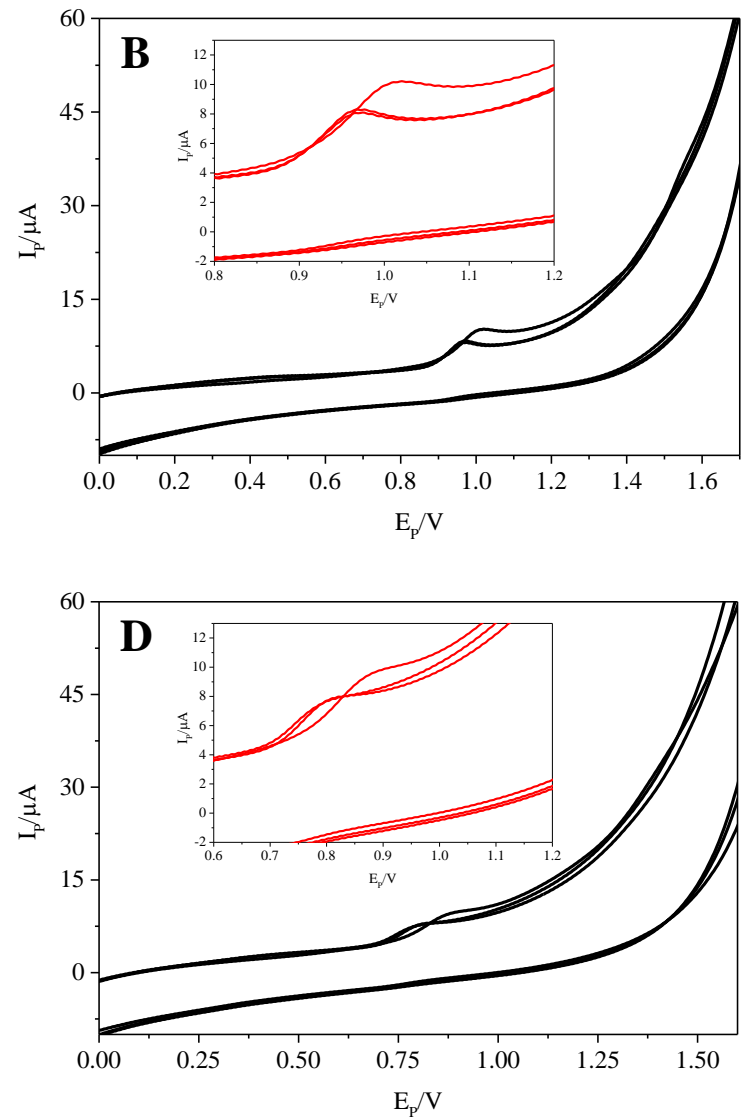

Figure 2. Cyclic voltammograms of $2.0 \times 10^{-4} \mathrm{M}$ cefpirome with GCE in $0.1 \mathrm{M} \mathrm{H}_{2} \mathrm{SO}_{4}(\mathrm{~A})$, pH $2 \mathrm{BRB}$ (B), pH $4.7 \mathrm{ABS}$ (C) and pH 7.0 PBS (D).

To investigate the effect of $\mathrm{pH}$ on peak current $\left(\mathrm{I}_{\mathrm{p}}\right)$ and peak potential $\left(\mathrm{E}_{\mathrm{p}}\right)$ were constructed using the related data of $\mathrm{pH}$ measurements in the presence of $2.0 \times 10^{-4}$ $\mathrm{M}$ cefpirome (Figure 3A). According to the $\mathrm{pH}$ study results, $E_{p}$ of cefpirome shifted to less positive values with increasing $\mathrm{pH}$. The curve of $\mathrm{E}_{\mathrm{p}} \mathrm{vs.} \mathrm{pH}$ (Figure 3B) exhibited a good linear relationship with the following equation

$$
E_{P}(V)=-0.054 p H+1.074 ; r=0.9945
$$

The slope of this equation $(54 \mathrm{mV}$ per $\mathrm{pH})$ showed that equal numbers of protons and electrons are involved in the redox behavior of cefpirome on GCE.

Moreover, the best peak shape, the highest current value, and good repeatability were obtained at $\mathrm{pH} 4.7$ ABS. Therefore, $\mathrm{pH}$ 4.7 ABS was chosen as the optimum supporting electrolyte and used for further analytical applications. 

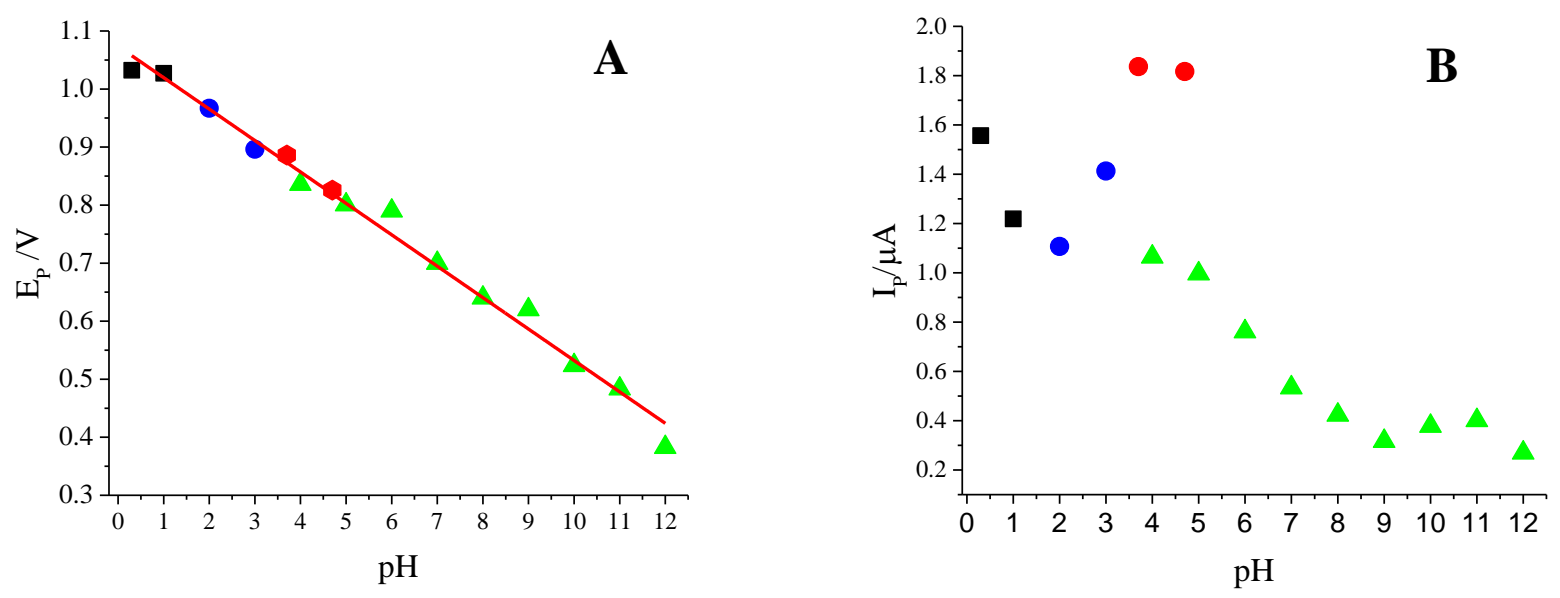

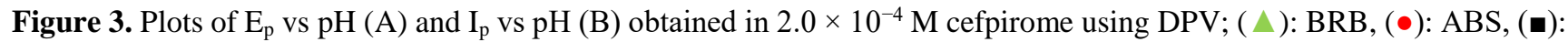
$\mathrm{H}_{2} \mathrm{SO}_{4},(\bullet)$ : PBS.

\subsection{Influence of scan rate on GCE}

In this study, the information about the electrochemical behavior of cefpirome was investigated by $\mathrm{CV}$ using the relationship between peak current and scan rate. The scan rate was changed in the range between 5 and $1000 \mathrm{mV} \mathrm{s}^{-1}$. This study was performed to understand whether the oxidation process is diffusion or adsorption-controlled in $2.0 \times 10^{-4} \mathrm{M}$ cefpirome on GCE. When the relationship between $\mathrm{I}_{\mathrm{p}}$ and $v^{1 / 2}$ was investigated (Figure 4A), a linear relationship was found with the equation below:

$$
\mathrm{I}_{\mathrm{P}}(\mu \mathrm{A})=0.266 v^{1 / 2}\left(\mathrm{mV} \mathrm{s}^{-1}\right)+0.16 ; \mathrm{r}=0.9966
$$

Therefore, it can be said that the oxidation process of cefpirome is controlled by diffusion on GCE. In addition, the curve of $\log \mathrm{I}_{\mathrm{p}} v s \log v$ (Figure 4B) exhibited a linear relationship with the regression equation below;

$$
\begin{gathered}
\log I_{P}(\mu A)=0.442 \log v\left(\mathrm{mV} \mathrm{s}^{-1}\right)-0.432 ; \\
r=0.9968
\end{gathered}
$$

For diffusion controlled process in an ideal reaction, the slope value of curve of $\log \mathrm{I}_{\mathrm{p}} v s \log v$ is 0.5 [22]. From the obtained data, the slope value of this plot was found as 0.442 , and this value was nearer to that of the desired value. This result also supported that oxidation of cefpirome was diffusion controlled.
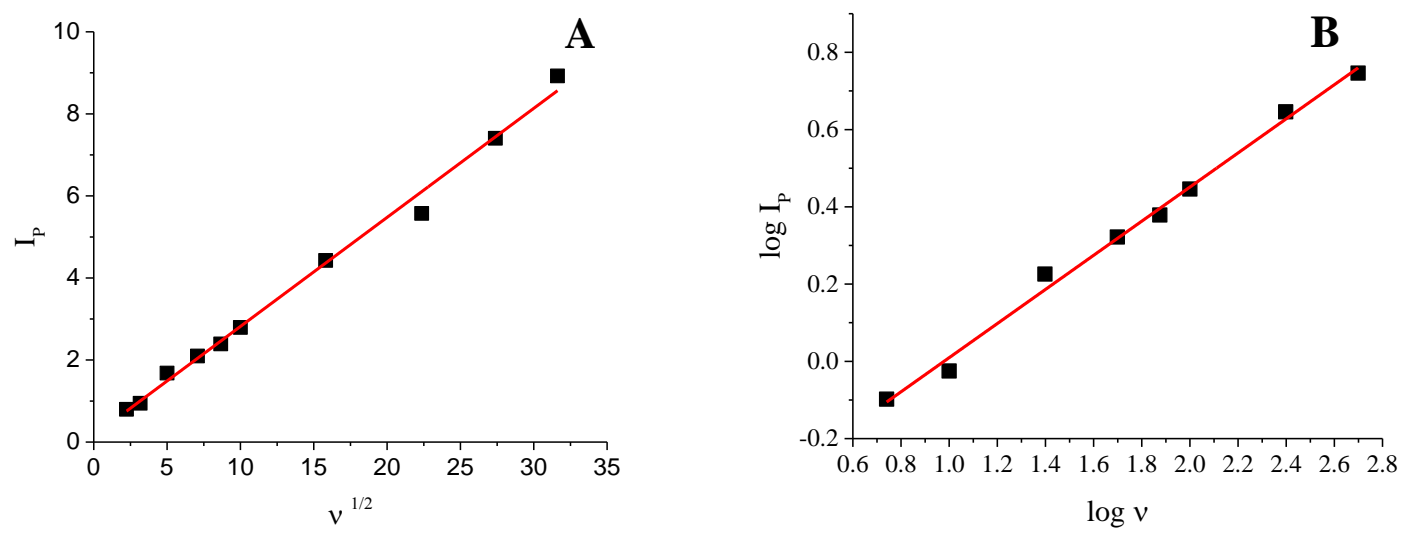

Figure 4. Curves of $\mathrm{I}_{\mathrm{p}} v s v^{1 / 2}(\mathrm{~A})$ and $\log \mathrm{I}_{\mathrm{p}} v s \log v(\mathrm{~B})$. 


\subsection{Validation of the method and determination of cefpirome in spiked human urine samples}

In this novel electrochemical method, a linear correlation between $I_{p}$ values and increasing cefpirome concentrations was obtained for the determination of cefpirome under the optimum conditions. Some of the
DP voltammograms from the linear range between 2$200 \mu \mathrm{M}$ cefpirome in bulk form and 2-10 $\mu \mathrm{M}$ cefpirome in human urine were shown in Figure 5A and Figure 5B. Also, the linearity of cefpirome for the DPV method was measured (Figure 5C and Figure 5D) with the following equations;

$$
\begin{gathered}
I_{P}(\mu A)=0.0089 C(\mu M)+0.0367 ; r=0.9975 \text { for bulk form } \\
I_{P}(\mu A)=0.021 C(\mu M)-0.0094 ; r=0.9979 \text { for human urine }
\end{gathered}
$$
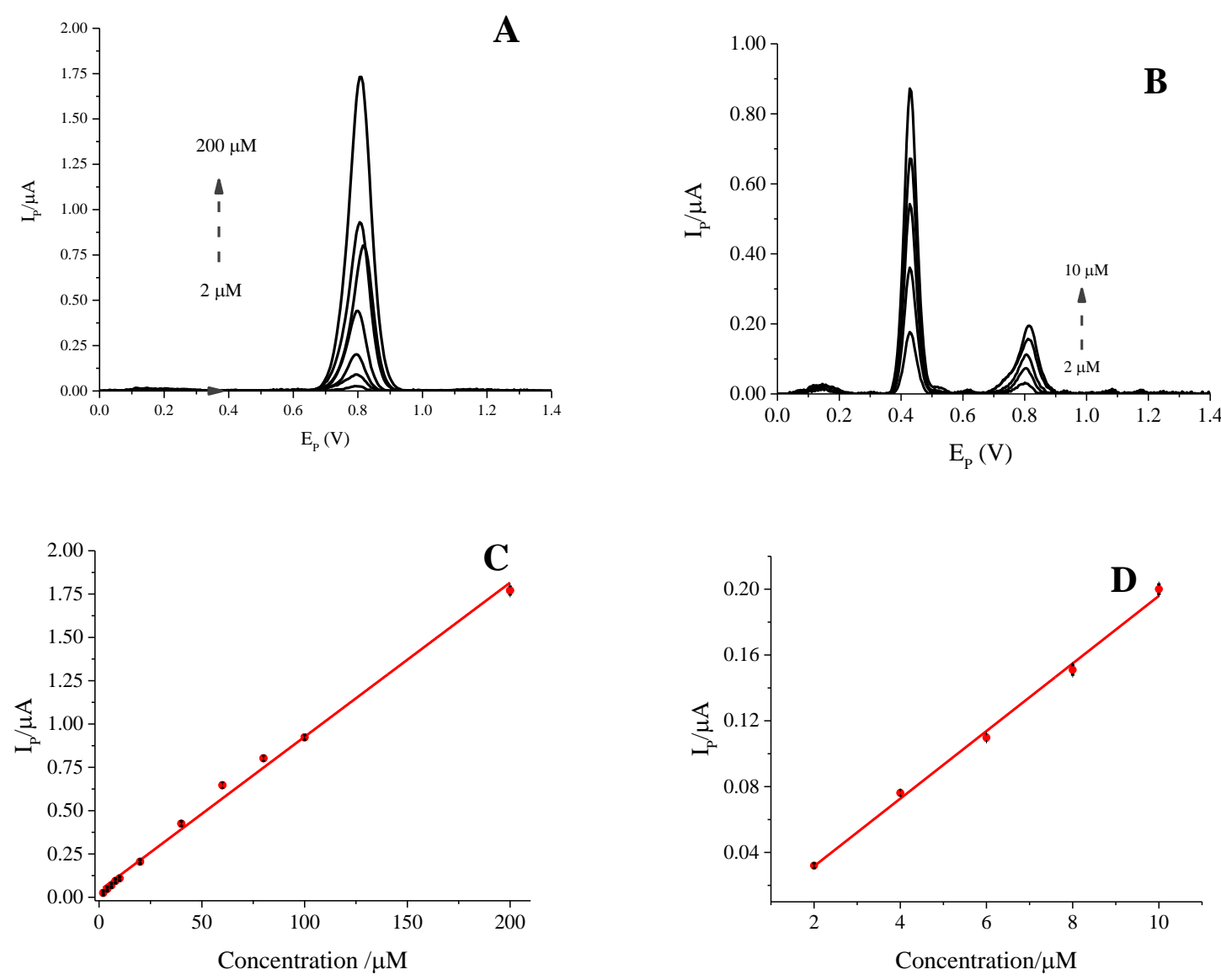

Figure 5. DP voltammograms obtained from increasing concentrations of cefpirome for bulk form (A) and for human urine (B) in $\mathrm{pH} 4.7$ ABS. Calibration curves of cefpirome for bulk form (C) and for human urine (D) in pH 4.7 ABS.

As a part of the validation of the proposed DPV method for the determination of cefpirome, LOD and LOQ values were evaluated in bulk form and human urine. LOD and LOQ values were calculated according to the following equations:

$$
\begin{aligned}
& \mathrm{LOD}=3 \mathrm{~s} / \mathrm{m} \\
& \mathrm{LOQ}=10 \mathrm{~s} / \mathrm{m}
\end{aligned}
$$

In these equations, $\mathrm{m}$ is the slope of calibration plots, and $\mathrm{s}$ is the standard deviation of peak current [23]. LOD values for bulk form and human urine were calculated using the calibration curve and found as $0.167 \mu \mathrm{M}$ and $0.101 \mu \mathrm{M}$, respectively. For the developed method, some characteristics of the validation results were presented in Table 1 . 
Table 1. Regression data of the calibration lines of cefpirome by DPV in bulk form and in human urine.

\begin{tabular}{ccc}
\hline Parameters & Bulk form & Human urine \\
\hline Measured Potential $(\mathrm{V})$ & 0.80 & 0.80 \\
Linearity range $(\mu \mathrm{M})$ & $2-200$ & $2-10$ \\
Slope $\left(\mu \mathrm{A} \mu \mathrm{M}^{-1}\right)$ & 0.0089 & 0.021 \\
Intercept $(\mu \mathrm{A})$ & 0.0367 & -0.0094 \\
Correlation coefficient & 0.9975 & 0.9979 \\
SE of slope & $2.08 \times 10^{-4}$ & $7.05 \times 10^{-4}$ \\
SE of intercept & 0.016 & 0.004 \\
LOD $(\mu \mathrm{M})$ & 0.17 & 0.10 \\
LOQ $(\mu \mathrm{M})$ & 0.50 & 0.34 \\
Within-day precision of peak current $(\% \mathrm{RSD}) *$ & 0.34 & 2.19 \\
Between-days precision of peak current $(\% \mathrm{RSD}) *$ & 1.16 & 2.51 \\
\hline
\end{tabular}

* Obtained from five experiments.

The repeatability of the developed method was studied by conducting five repetitive measurements for bulk form and human urine at fixed cefpirome concentrations $(20 \mu \mathrm{M}$ for bulk form and $6.0 \mu \mathrm{M}$ for human urine). For within-day precision, the relative standard deviation (RSD \%) values of peak current were calculated as 0.34 and 2.19 for bulk form and human urine, respectively. Moreover, between-days precision was investigated by conducting five repetitive measurements at the same cefpirome concentrations. The RSD \% values of peak current were found as 1.16 and 2.51 for bulk form and human urine, respectively. Therefore, it can be clearly said that the method is precise based on obtained results.

Moreover, recovery studies were performed by the standard addition method. The recovery $\%$ and Bias $\%$ were presented in Table 2, and they were all in acceptable ranges. So, the results of recovery studies showed that the developed method is accurate.
Table 2. Results obtained for cefpirome determination from spiked human urine samples.

\begin{tabular}{cc}
\hline Parameters & Human urine \\
\hline Reference concentration $(\mu \mathrm{M})$ & 6.00 \\
Observed concentration $(\mu \mathrm{M})$ & 6.18 \\
Number of experiments & 5 \\
Average recovery \% & 103.09 \\
RSD \% of recovery & 1.42 \\
Bias \% & -3.09 \\
\hline
\end{tabular}

To sum up, when the developed method is compared to literature studies (Table 3), it can be said that a more sensitive DPV method was developed with a $0.101 \mu \mathrm{M}$ $\left(0.06 \mu \mathrm{g} \mathrm{mL}^{-1}\right)$ detection limit. In addition, this method is both low-cost and more environmentally friendly as there was very simple preparation procedure, which is one of the requirements of chromatographic methods, and this method did not require organic solvent consumption.

Table 3. Comparison of major characteristics in literature studies for determination of cefpirome.

\begin{tabular}{ccccc}
\hline Method & Linear range & LOD & Applications & Ref. \\
\hline LC-MS/MS & $0.7-100 \mu \mathrm{g} \mathrm{mL}^{-1}$ & $0.30 \mu \mathrm{g} \mathrm{mL}^{-1}$ & Pork muscle & {$[6]$} \\
HPLC & $20-30 \mu \mathrm{g} \mathrm{mL}^{-1}$ & $2.38 \mu \mathrm{g} \mathrm{mL}^{-1}$ & Bulk form & {$[7]$} \\
HPLC & $0.5-200 \mu \mathrm{g} \mathrm{mL}^{-1}$ & $0.1 \mu \mathrm{g} \mathrm{mL}^{-1}$ & Human serum & {$[8]$} \\
HPLC & up to $500 \mu \mathrm{g} \mathrm{mL}^{-1}$ & $0.6 \mu \mathrm{g} \mathrm{mL}^{-1}$ & Human milk and urine & {$[9]$} \\
HPLC & $5.0-50 \mu \mathrm{g} \mathrm{mL}^{-1}$ & $1.45 \mu \mathrm{g} \mathrm{mL}^{-1}$ & Bulk form & B10] \\
DPV & $100-600 \mu \mathrm{g} \mathrm{mL}^{-1}$ & $5.54 \mu \mathrm{g} \mathrm{mL}^{-1}$ & Bulk form & [4] \\
SWV & $1.03-41.17 \mu \mathrm{g} \mathrm{mL}^{-1}$ & $0.09 \mu \mathrm{g} \mathrm{mL}^{-1}$ & Bulk form & Proposed method \\
\hline
\end{tabular}

DPV: Differential pulse voltammetry, HPLC: High-performance liquid chromatography, LC-MS/MS: Liquid chromatography-tandem mass spectrometry, SWV: Square wave voltammetry 


\subsection{Interference effects in the determination of cefpirome}

Selectivity is one of the most important validation parameters of developed analytical methods. It is not desirable for different species to interfere with the compound to be analyzed [24]. To demonstrate the selectivity of the developed method, cefpirome determination was performed in the presence of some organic species, including ascorbic acid, uric acid, dopamine, glucose, and $\mathrm{Na}^{+}, \mathrm{K}^{+}, \mathrm{Ca}^{+2}$ and $\mathrm{NO}_{3}^{-}$ions. In the presence of 1:1,1:10, and 1:100 molar ratio of the interfering species, recovery (\%) values were determined. For this purpose, the peak current of 10 $\mu \mathrm{M}$ cefpirome in the standard solution was compared to the peak currents of cefpirome in the presence of interfering species (Table 4). While $10 \mu \mathrm{M}$ cefpirome was also determined in the presence of 1:1 and 1:10 molar ratios of ascorbic acid, uric acid, $\mathrm{Na}^{+}, \mathrm{K}^{+}, \mathrm{Ca}^{+2}$ and $\mathrm{NO}_{3}^{-}$within the $10 \%$ tolerance limit, interference effect was observed in the presence of dopamine and glucose. Moreover, cefpirome current did not change more than $10 \%$ in the presence of 1:100 molar ratio of ascorbic acid, $\mathrm{Na}^{+}, \mathrm{K}^{+}, \mathrm{Ca}^{+2}$ and $\mathrm{NO}_{3}^{-}$.

Table 4. $10 \mu \mathrm{M}$ cefpirome assayed in the presence of some interfering species

\begin{tabular}{cccc}
\hline \multirow{2}{*}{ Interfering species } & \multicolumn{3}{c}{ Recovery $(\%)$ by DPV } \\
\cline { 2 - 4 } & $1: 1(\mathrm{M} / \mathrm{M})$ & $1: 10(\mathrm{M} / \mathrm{M})$ & $1: 100(\mathrm{M} / \mathrm{M})$ \\
\hline Ascorbic acid & $102.69 \pm 0.003$ & $104.41 \pm 0.02$ & $110.57 \pm 0.01$ \\
Uric acid & $108.77 \pm 0.02$ & $106.67 \pm 0.02$ & $116.49 \pm 0.01$ \\
Dopamine & $87.35 \pm 0.02$ & - & - \\
Glucose & $88.14 \pm 0.02$ & - & - \\
$\mathrm{Na}^{+}$ & $95.44 \pm 0.01$ & $94.74 \pm 0.01$ & $95.26 \pm 0.02$ \\
$\mathrm{~K}^{+}$ & $94.21 \pm 0.01$ & $96.14 \pm 0.005$ & $92.28 \pm 0.01$ \\
$\mathrm{Ca}^{+2}$ & $96.32 \pm 0.01$ & $92.63 \pm 0.02$ & $90.35 \pm 0.02$ \\
$\mathrm{NO}_{3}^{-}$ & $96.67 \pm 0.01$ & $96.91 \pm 0.01$ & $95.23 \pm 0.003$ \\
\hline
\end{tabular}

\section{Conclusions}

In the novel proposed method, the electrochemical behavior of cefpirome was investigated by DPV using GCE. The effect of the type and $\mathrm{pH}$ of supporting electrolytes and scan rate in optimum supporting electrolyte were optimized. The developed electrochemical method provided a simple low cost and fast analysis for the determination of cefpirome from bulk form and human urine samples. Especially, the proposed method is suitable for screening purposes, compared to other analytical methods. The proposed method was also validated in accordance with ICH guidelines. In this study, a lower detection limit was obtained than the reported LC-MS/MS, HPLC, DPV, and SWV methods.

In this study, the sample preparation procedure is very simple for determination from human urine samples. The sample preparation procedure has a simple and convenient one-step precipitation method. Therefore, this DPV method is more feasible than other methods for cefpirome detection in human urine samples. Moreover, satisfactory results were obtained in the determination of cefpirome in spiked human urine samples. So, it can be said that the proposed method is applicable for real sample analysis. In addition, the novel developed method can be adopted for pharmacokinetic studies, clinical applications, or quality control laboratories.

\section{Acknowledgment}

The authors would like to thank the Ankara University Scientific Research Projects Commission for financial support (Project No: 18B0237001).

\section{Conflicts of interest}

The authors state that did not have conflict of interests. 


\section{References}

[1] Nawaz M., Arayne M. S., Sultana N., Abbas H. F., Investigation of interaction studies of Cefpirome with ACE-Inhibitors in various buffers, Spectrochim. Acta - Part A Mol. Biomol. Spectrosc., 137 (2015) 1050-1054.

[2] Kong X. X., Jiang J. L., Qiao B., Liu H., Cheng J. S., Yuan Y. J., The biodegradation of Cefuroxime, Cefotaxime and Cefpirome by the Synthetic Consortium with Probiotic Bacillus Clausii and investigation of their potential biodegradation pathways, Sci. Total Environ., 651 (2019) 271-280.

[3] Zalewski P., Skibiński R., SzymanowskaPowałowska D., Piotrowska H., Kozak M., Pietralik Z., Bednarski W., Cielecka-Piontek J., The Radiolytic Studies of Cefpirome Sulfate in the solid state, J. Pharm. Biomed. Anal., 118 (2016) 410-416.

[4] Jain R., Vikas, Voltammetric Determination of Cefpirome at Multiwalled Carbon Nanotube modified Glassy Carbon Sensor based electrode in bulk form and Pharmaceutical formulation, Colloids Surfaces B. Biointerfaces, 87(2) (2011) 423426.

[5] Hong Y. H., Xu X. L., Li W. Q., Xu B. Z., Wu H. Q., Cheng Y., Chen H., Zhang B. S., Zhang F., A high-accuracy screening method of 44 Cephalosporins in meat using liquid Chromatography Quadrupole-Orbitrap hybrid mass spectrometry, Anal. Methods, 9(46) (2017) 6534-6548

[6] Li W., Shen H., Hong Y., Zhang Y., Yuan F., Zhang F., Simultaneous determination of 22 Cephalosporins drug residues in Pork Muscle using liquid Chromatography-Tandem mass spectrometry, J. Chromatogr. B. Anal. Technol. Biomed. Life Sci., 1022 (2016) 298307.

[7] Zalewski, P., Skibiński R., Cielecka-Piontek J., Bednarek-Rajewska K., Development and validation of stability-indicating HPLC method for determination of Cefpirome Sulfate, Acta Pol. Pharm., 71(5) (2014) 731736.
[8] Breilh D., Lavallee C., Fratta A., Ducint D., Cony-Makhoul P., Saux M. C., Determination of Cefepime and Cefpirome in human serum by high-performance liquid Chromatography using an ultrafiltration for antibiotics serum extraction, J. Chromatogr. B Biomed. Sci. Appl., 734(1) (1999) 121-127.

[9] Kearns G.L., Johnson V.A., Hendry I.R., Wells T.G., Microanalytical highperformance liquid Chromatographic assay for Cefpirome in human milk and Urine, $J$. Chromatogr., 574(2) (1992) 356-60.

[10]Elghobashy M. R., Bebawy L. I., Abbas S. S., and Shokry R. F., Stability-indicating HPLC and RP-TLC determination of Cefpirome Sulfate with kinetic study, Chromatographia, 76 (17-18) (2013) 1141-1151.

[11] Watanabe E., Review of Sample Preparation Methods for Chromatographic analysis of Neonicotinoids in agricultural and environmental matrices: from classical to state-of-the-art methods, J. Chromatogr. A., 462042 (2021).

[12] Mattrey F. T., Makarov A. A., Regalado E. L., Bernardoni F., Figus M., Hicks M. B., Zheng J., Wang L., Schafer W., Antonucci V., Hamilton S., Zawatzky K., and Welch C.J., Current challenges and future prospects in Chromatographic method development for pharmaceutical research, TrAC - Trends Analyt Chem, 95 (2017) 36-46.

[13] Tobiszewski M., Namieśnik J., Direct Chromatographic methods in the context of green analytical chemistry, TrAC - Trends Analyt. Chem., 35 (2012) 67-73.

[14] Ganjali M. R., Gupta V. K., Faridbod F., Norouzi P., Electrochemical Determination of Lanthanides Series., In: Ganjali M. R., Gupta V. K., Faridbod F., Norouzi P., (Eds). In Lanthanides Series Determination by Various Analytical Methods., Amsterdam: Elsevier, (2016).

[15]Glasscott M. W., Vannoy K. J., Iresh Fernando P.U.A., Kosgei G. K., Moores L. C., Dick J. E., Electrochemical sensors for the detection of Fentanyl and its analogs: 
foundations and recent advances, $\operatorname{Tr} A C$ Trends Analyt. Chem., 132 (2020) 16037.

[16]Meenakshi S., Rama R., Pandian K., Gopinath S.C.B., Modified electrodes for electrochemical determination of Metronidazole in drug formulations and biological samples: An overview, Microchem. J., 165 (2021) 106151.

[17]Boumya W., Taoufik N., Achak M., Bessbousse H., Elhalil A., Barka N., Electrochemical sensors and biosensors for the determination of diclofenac in pharmaceutical, biological and water samples, Talanta, 3 (2021) 100026.

[18]Boumya W., Taoufik N., Achak M., Barka N. Chemically modified carbon-based electrodes for the determination of Paracetamol in drugs and biological samples, J. Pharm. Anal., 11(2) (2020) 138-154.

[19]Li T., Xu J., Zhao L., Shen S., Yuan M., Liu W., Tu Q., Yu R., Wang J., Au nanoparticles/poly(caffeic acid) composite modified glassy carbon electrode for voltammetric determination of Acetaminophen, Talanta, 159 (2016) 356364.

[20] ICH Expert Working Group, ICH guideline Q1A(R2) stability testing of new drug substances and products, Int. Conf. Harmon., 24 (2003).

[21] Strenkoski L.C., Nix D.E., Cefpirome clinical pharmacokinetics, Clin Pharmacokinet., 25(1993) 263-273.

[22]Deepa S., Swamy B. E. K., Pai K. V. A., Surfactant SDS modified carbon paste electrode as an enhanced and effective electrochemical sensor for the determination of Doxorubicin and Dacarbazine its applications: a voltammetric study, $J$. Electroanal. Chem., 879 (2020) 114748.

[23] Kurbanoglu S., Uslu B., Ozkan S.A., Validation of Analytical Methods for the Assessment of Hazards in Food., In: Grumezescu A. M., Holban A. M., (Eds). Food Safety and Preservation, Modern Biological Approaches to Improving Consumer Health., London: Academic Press, 2018.

[24] Dogan-Topal B., Uslu B., Ozkan S. A., Voltammetric studies on the hiv-1 inhibitory drug efavirenz: the interaction between DsDNA and drug using electrochemical DNA biosensor and adsorptive stripping voltammetric determination on disposable pencil graphite electrode, Biosens. Bioelectron., 24(8) (2009) 2358-2364. 